ISSN 1518-3483

Licenciado sob uma Licença Creative Commons

\title{
Da epistemologia clássica da educação à inclusão escolar: desafios e perspectivas
}

\author{
From the classical epistemology of education to school \\ inclusion: challenges and prospects
}

\section{De la epistemología de la educación clásica a la inclusión escolar: desafíos y perspectivas}

\section{Rita Vieira de Figueiredo ${ }^{[a]}$, Lindomar Wessler Boneti ${ }^{[b]}$, Jean-Robert Poulin ${ }^{[c]^{*}}$}

[a] Universidade Federal do Ceará (UFC), Fortaleza, CE, Brasil

[b] Pontifícia Universidade Católica do Paraná (PUCPR), Curitiba, PR, Brasil

[c] Universidade de Québec à Chicoutimi (UQAC), Canadá

\section{Resumo}

Dedica-se neste artigo a analisar as especificidades da educação inclusiva, da implementação institucional à prática da sua ação. Argumenta-se que a educação inclusiva se apresenta frente a um desafio o qual se constitui no descompasso entre a epistemologia clássica da educação e a da educação inclusiva. Isto é, se de um lado a partir da epistemologia clássica a ação escolar utiliza como pressuposto básico a homogeneidade, funcionalidade

* RVF: Pós-Doutora, e-mail: aee.rita@gmail.com LWB: Pós-Doutor, e-mail: lindomar@boneti.com JRP: Doutor em psicopedagogia, e-mail: jean-robert_poulin@uqac.ca 
e evolução, por outro lado, o pressuposto básico da educação inclusiva é que as diferenças se constituem em fator construtivo, a partir de trocas de experiências advindas das diferentes experiências de vida construídas nas especificidades e singularidades sociais. Porém, se a institucionalidade da escola, suas regras, normas e valores, continua assentada no pressuposto da epistemologia clássica da educação, o mundo social e acadêmico age de forma a criar caminhos que viabilizam a educação inclusiva, como é o caso da conquista da legislação e a pressão feita sobre a escola no sentido de acolher as diferenças e as singularidades sociais.

Palavras-chave: Políticas educacionais. Epistemologia da educação. Educação Inclusiva.

\begin{abstract}
This article is dedicated to examine the specificities of inclusive education, from the institutional implementation of the practice to the action. It is argued that inclusive education presents a challenge in front of which constitutes the gap between classical epistemology of education and inclusive education. That is, if a side from classical epistemology school action uses as a basic assumption homogeneity, functionality and evolution, on the other hand, the basic assumption of inclusive education is that the differences constitute constructive factor, from exchanges the resulting experiences of the different life experiences built on specifics and social singularities. But if the school institutions, rules, norms and values, still seats on the assumption of classical epistemology of education, social and academic world acts to create paths that enable inclusive education, such as the conquest of legislation and the pressure made on the school in order to welcome the differences and social singularities.
\end{abstract}

Keyword: Educational policies. Epistemology of education. Inclusive education. 


\section{Resumen}

Se dedica a este artículo para examinar los aspectos específicos de la educación inclusiva, desde la implementación institucional hasta la práctica de su acción. Se argumenta que la educación inclusiva constituye un desafío frente a la cual constituye la brecha entre la epistemología clásica de la educación y la educación inclusiva. Es decir, si un lado de la acción escolar la epistemología clásica es utilizada teniendo como base la homogeneidad, funcionalidad y evolución, por otro lado, el supuesto básico de la educación inclusiva es que las diferencias constituyen el factor constructivo de los intercambios las experiencias resultantes de las diferentes experiencias de vida basadas en características especificas y singularidades sociales. Pero si las instituciones escolares, reglas, normas y valores, aún están sentados en el supuesto de la epistemología clásica de la educación, mundo académico y social actúa para crear caminos que permiten a la educación inclusiva, como la conquista de la legislación y la presión que se hizo en la escuela con el fin de acoger las diferencias y singularidades sociales.

Palabras clave: Políticas educativas. Epistemología de la educación. La educación inclusiva.

\section{Introdução}

Em muitas sociedades democráticas a escolarização e o desempenho escolar em contexto inclusivo se constituem uma poderosa estratégia para melhorar o processo de aprendizagem das crianças e dos estudantes em geral e consequentemente representa uma via de desenvolvimento importante para o país.

De acordo com Moreau, Stanke e Lafontaine (2014), a organização das Nações Unidas para a Educação, a Ciência e a Cultura (UNESCO) afirma que muitos países em diferentes continentes implementaram ações visando aperfeiçoar os serviços educativos e contribuir para um melhor desempenho escolar dos alunos em contexto de inclusão escolar (UNESCO, 2009). Os Estados Unidos e o Canadá vêm realizando ações e 
políticas educativas visando promover a inclusão escolar. (FIGUEIREDO, 2015) No Canadá os governos provinciais têm realizado reformas na educação e implementado diversas ações políticas com o objetivo de dar sustentação ao "desempenho escolar dos alunos incluindo aqueles que apresentam deficiência ou condições particulares de aprendizagem" (MOREAU, STANKE e LAFONTAINE, 2014, p.10).

Abordar a educação inclusiva é tratar necessariamente da educação enquanto direito universal, resultado de uma conquista social, e da diferença como um dado da realidade humana que se expressa nas práticas da educação escolar.

Este é o foco central da discussão deste artigo. Inicialmente busca-se confrontar os pressupostos epistemológicos dos dois campos, o da educação clássica e o da educação inclusiva, na perspectiva de buscar compreender as possibilidades e limites desta ação. Em seguida, na perspectiva de avaliar os avanços percorridos neste campo, esboça-se um quadro dos progressos realizados em termos de Educação Inclusiva no Brasil especialmente no que se refere aos avanços institucionais na área das Políticas educacionais, da questão do acesso às escolas regulares especialmente no que se refere às práticas pedagógicas no contexto das diferenças. Por fim, argumenta-se que o pressuposto da prática colaborativa se constitui caminho para a ação da educação inclusiva na perspectiva da superação da epistemologia clássica da educação e suas amarras institucionais a partir das suas normas, regras e valores tradicionais.

Ou seja, o argumento central deste artigo é que o desafio da educação inclusiva se encontra no descompasso entre a epistemologia clássica da educação e a da educação inclusiva. Isto é, se de um lado a partir da epistemologia clássica a ação escolar utiliza como pressuposto básico a homogeneidade, funcionalidade e evolução, por outro lado, o pressuposto básico da educação inclusiva é que as diferenças se constituem em fator construtivo, a partir de trocas de experiências advindas das diversificadas experiências de vida construídas nas diferenças e singularidades sociais. Porém, se a institucionalidade da escola, suas regras, normas e valores, continua assentada no pressuposta da epistemologia clássica da 
educação, o mundo social age de forma a criar caminhos que viabilizam a educação inclusiva, como é o caso da conquista da legislação e a pressão feita pelo social sobre a escola no sentido de receber as diferenças e as singularidades sociais.

\section{A epistemologia clássica da educação e os entraves da inclusão}

A epistemologia clássica da educação tem origem a partir de um movimento histórico associado à construção da racionalidade moderna a qual designou-se à escola dar conta e fazer dos sujeitos sociais, sujeitos modernos, funcionais e evolutivos. Para isto, alguns elementos se fazem importantes os quais nem sempre têm afinidade com os pressupostos da educação inclusiva tais como a homogeneidade, a universalidade dos parâmetros de verdade, a funcionalidade, a evolução, etc.

Os séculos XV, XVI e XVII testemunharam um expressivo movimento de construção da base da ciência e do Estado Moderno, o que se constituiu fundamento clássico epistemológico das políticas e ações educacionais. Este movimento, apresentando a construção da "razão" como meta, dedicou-se em torno de dois principais enfoques: o método científico e a organização social (o Estado). "Razão" designava a busca de uma sociedade nova, comparativamente à sociedade medieval, a busca de uma sociedade racional com base na cientificidade na utilização de um método de explicação do real e da organização social. Assim, de um lado, Francis Bacon (1561-1626) e Descartes (1596-1650) contribuíram com a construção das bases epistemológicas do que se convencionou chamar de Ciência Moderna, enfocando prioritariamente o método científico. De outro lado, a "razão", como sinônimo de cientificidade, de verdade, estava presente também na busca da superação do Estado medieval. Hobbes (1588-1679), Locke (1632-1704) e Rousseau (1712-1778), com perspectivas diferentes em relação ao "Contrato Social" sedimentaram as bases epistemológicas da organização social, o Estado, na modernidade.

Portanto, neste período histórico já se atribuiu duas responsabilidades básicas para a escola moderna: em primeiro lugar a prática do 
conceito de verdade racional associada não apenas à ciência, mas ao agir político e institucional, como é o caso da política educacional e o papel do Estado em relação à escola. Ou seja, o conceito de escola moderna passa a ser associado a uma verdade científica tanto do ponto de vista institucional, suas regras e normas, quanto do ponto de vista da prática educativa, a didática, o comportamento pessoal na escola, etc. Em segundo lugar, a escola moderna passa a praticar um conhecimento, produzir e transmitir, utilizando o parâmetro de verdade universal, a partir do pressuposto de que a verdade é uma só independentemente das diferentes realidades no mundo. Assim, destituiu-se a possibilidade de se atribuir verdade a saberes produzidos no âmbito de singularidades fora do parâmetro tido como verdade universal.

Dando continuidade a este movimento histórico da construção da razão moderna, aliando ciência e Estado, no Século XVIII, um novo ingrediente passa a constituir base da epistemologia moderna, a operacionalidade da ciência. Ou seja, a verdade para ser verdade, teria que estar associada à produção de resultados, ou seja, à funcionalidade. Ou seja, ganha ênfase a técnica como sinônimo de verdade. Se até então ciência e Estado vinham se apresentando casados como sinônimo de racionalidade, a partir do Século XVIII, com o advento da técnica, esta se apresenta como um novo ingrediente de verdade, quando se associa à produção industrial, à lógica do próprio capitalismo.

Portanto, trata-se de um movimento histórico de construção de uma unificação entre um conceito de verdade científica e um conceito de verdade institucional, passando a se constituir em epistemologia clássica da escola até nos dias atuais. Na prática, isto significa que a institucionalidade da escola, o seu conjunto de regras, normas e valores, está associada a um saber que se diz universal, com dificuldades de atribuir veracidade aos outros saberes (originais) e diferentes daqueles. De acordo com essa lógica também se exige a funcionalidade do saber (o saber apreendido na escola deve servir para alguma coisa prática, do contrário fica sem sentido), construindo assim um sujeito social com capacidade de evolução, transformação (como a ação industrial) e funcionalidade. Com isto 
instala-se o preceito de associar o modelo cultural burguês e hegemônico associado à atividade industrial, como sinônimo de civilidade, atribuindo à escola o papel de o implementar.

Porém, a racionalidade técnica como sinônimo de verdade começa a ser questionada, abrindo caminhos um modelo de ensino como é o caso da educação inclusiva. A Razão Moderna tendo como base a técnica começa a ser questionada justamente com o advento de problemas sociais típicos da contemporaneidade como foi o caso das duas guerras mundiais, a destruição em massa graças a técnica, a crise ambiental, o abalo das identidades suprimidas pelo pressuposto da homogeneidade advindo com o procedimento técnico, a indiferença com as singularidades, etc. como bem analisa Boaventura de Souza Santos (1987, p. 9-15).

A crise da Razão Moderna se expressa através de uma dinâmica social insurgente a qual extrapola o âmbito institucional dos movimentos sociais transnacionais e debates acadêmicos para o mundo do Ser e da busca pela construção das identidades individuais e coletivas, onde passa a ter guarida os caminhos iniciais da educação inclusiva.

No mundo acadêmico faz-se importante lembrar o debate originado desde o início do Século XX, o qual ficou conhecido como a Teoria Crítica, da Escola de Frankfurt. Intelectuais como Max Horkhaimer, Theodor Adorno e Hebert Marcuse, Jürgen Habermas, etc., construíram notoriedade ao questionarem o pressuposto associando Razão à Técnica. Dentre muitas obras produzidas por este grupo de intelectuais sobre a temática citada, indispensável citar Técnica e Ciência como "ideologia” de Habermas (1970).

Mas a dinâmica social contemporânea, ela própria extrapola os muros da academia construindo um debate em torno da elaboração e da implementação de uma política educacional voltada às diferenças e as singularidades sociais. Com isto destitui-se o modelo cultural burguês e hegemônico como sinônimo de civilidade a partir, especialmente, da ocorrência de eventos diversos envolvendo o mundo social. No caso brasileiro, pode-se considerar como um primeiro caminho deste processo o advento 
da urbanização quando afloram diferenciações de grupos sociais distintos nas periferias urbanas (BONETI, 2013, p. 270).

Esse processo de mudança também está associado a outros eventos, como por exemplo: a chegada ao Brasil de estudos científicos, etnográficos, sociológicos e antropológicos, para os quais o mundo cultural passou a ter outro enfoque, diferente daquele associado aos saberes e costumes da classe burguesa. Contribuiu com estes debates também os estudos estruturais de cultura de Lévi-Strauss e a análise funcionalista da cultura de Malinowski como expressão da vida no presente, destituindo assim a relação entre a cultura e a evolução social. Outro evento importante que contribuiu com este debate, a Semana de Arte Moderna de 1922, a qual contribuiu com a quebra do preceito que associa cultura ao mundo formal burguês. Nesta época chega ao Brasil a influência de algumas manifestações sociais e culturais americanas, como é o caso do hip-hop, as artes, a música (blues e jazz) e a literatura, influenciando a expressão cultural da periferia urbana (BONETI, 2013, p. 270).

Esta fase de manifestações culturais e sociais impactaram sobre uma nova forma de ver a educação e a ação escolar, a partir de um novo projeto de política educacional. Como exemplo deste processo se tem o Manifesto dos Pioneiros da Escola Nova (1932). Mesmo que, contraditoriamente, se de um lado representou a expressão de intelectuais almejando um modelo educacional nacional comprometido com o projeto de modernidade, por outro lado destitui-se a unicidade das finalidades educacionais ao projeto burguês e de classe. Constituiu-se, assim, um caminho para se construir uma política educacional com a perspectiva de receber na escola crianças advindas de diferentes camadas sociais.

Os novos processos sociais anunciados acima dão origem a um novo debate, o da presença na escola das diferenças e dos sujeitos advindos de diferentes camadas sociais. Este novo debate ocorrido no mundo social penetra no mundo da política quando tem origem políticas educacionais voltadas à inclusão social e educacional. 


\section{Dispositivos legais para a inclusão no Brasil: caminhos da inclusão}

Certamente este debate originado de diferentes eventos sociais no Brasil e no mundo, contribuíram significativamente para a implementação de instrumentos legais para a inclusão social e educacional no Brasil. Diferentes dispositivos legais em nosso país e fora dele asseguram o direito de todas as pessoas à educação. Dentre esses dispositivos destaca-se a Convenção sobre os Direitos das Pessoas com Deficiência da ONU (2006), da qual o Brasil é signatário, e a Política Nacional de Educação Especial na Perspectiva da Educação Inclusiva (2008). A Convenção sobre os Direitos das Pessoas com Deficiência reconhece o direito das pessoas com deficiência à educação. Para efetivar esse direito sem discriminação e com base na igualdade de oportunidades, o sistema educacional inclusivo deve ser assegurado em todos os níveis, bem como o aprendizado ao longo de toda a vida. De acordo com a Convenção os Estados Partes assegurarão às pessoas com deficiência a possibilidade de adquirir as competências práticas e sociais necessárias de modo a facilitar a plena e igual participação no sistema de ensino e na vida em comunidade (FIGUEIREDO, 2015).

A Política Nacional de Educação Especial na Perspectiva da Educação Inclusiva de 2008 propõe mudança de valores, atitudes e práticas educacionais para atender a todos os estudantes, sem nenhum tipo de discriminação. Ela pretende implementar uma educação de qualidade e assegurar a inclusão escolar de todos os alunos e os serviços da Educação Especial que é uma modalidade de ensino que perpassa todos os níveis e etapas da educação básica ao ensino superior.

Esta Política prevê que o ensino comum responda pela escolarização de todos os alunos nas classes comuns de ensino, e ofereça os serviços da Educação Especial, dentre eles, o Atendimento Educacional Especializado - AEE. Este atendimento de acordo com a Política do MEC deve assegurar que os alunos público alvo da educação especial aprendam o que é diferente do currículo do ensino comum e que é necessário para que possam ultrapassar as barreiras impostas pela deficiência. Este Serviço tem como papel oportunizar a inclusão, distanciando os alunos de 
centros especializados públicos e privados, que os excluem de um ambiente de formação comum a todos, discriminando-os e segregando-os e ainda porque é neste espaço que os problemas do aluno devem ser tratados e discutidos com todos os profissionais que com ele atuam (BRASIL, 2008).

\section{A Inclusão no debate acadêmico}

O direcionamento político acima apresentado expresso tanto na Política Nacional de Educação Especial na Perspectiva da Educação inclusiva quanto na Convenção da ONU está em consonância com uma visão de escola inclusiva que remete à ideologia e a politicas educativas que se fundem sobre um sistema e uma só via (a da escola comum), na qual cada aluno tem o direito de ser escolarizado em um estabelecimento próximo de sua casa. (THOMAZETI, 2008 apud MOREAU, STANKÉ e LAFONTAINE, 2014, p.10).

Segundo Moreau, Stanké e Lafontaine (2014, p. 10), a escola Inclusiva promove a acessibilidade e a educação. "Trata-se de um olhar para além da diferença do aluno, e, enxergar elementos do ambiente que constituem obstáculos às suas aprendizagens" (tradução livre) e a sua participação social a fim de oferecer os ajustamentos e as modificações que se fazem necessárias.

Segundo Figueiredo (2015), a escola que inclui e oportuniza aprendizagem de todos os alunos removendo as barreiras que possam dificultar a apropriação de conhecimentos e saberes requer uma nova forma de ensinar e de aprender. Implica na transformação da escola que em sua essência é um projeto de sociedade: uma sociedade que acolhe e da oportunidade educativa a todos.

Uma das grandes marcas da escola inclusiva é a valorização do papel social dos professores e alunos (POULIN, 2010). Para Poulin esta valorização do papel social do aluno repousa sobre a noção de contribuição que engloba em si mesma a noção de cooperação, constantemente convocada na literatura que trata da educação inclusiva. Segundo o autor, é o reconhecimento dessa contribuição, especialmente em contexto de 
cooperação que constitui a pedra angular da valorização do papel social do indivíduo.

Ainda de acordo com Poulin (2010) a escola inclusiva assenta-se sobre o princípio da cooperação. A sala de aula nesse contexto se constitui em um reagrupamento no qual cada aluno deve colaborar com o processo de construção do conhecimento dentro de suas possibilidades (POULIN, 2010). O autor argumenta que a educação inclusiva resguarda os princípios de como ocorre a construção do conhecimento: a partir da atividade do sujeito diante das solicitações e desequilíbrios do meio e que o sujeito de conhecimento é um sujeito autônomo e a cooperação é elemento central do processo de aprendizagem. Cooperar, participar ativamente das atividades escolares constitui um desafio para os alunos que apresentam deficiência, especialmente para aqueles com deficiência intelectual que na maioria das vezes se sentem inibidos frente às exigências das tarefas. Algumas estratégias didáticas podem contribuir para favorecer a participação desses alunos na classe. (FIGUEIREDO, 2015).

Uma dessas estratégias, a aprendizagem cooperativa foi investigada por Poulin, Figueiredo, Silva e Gomes, (2014) para verificar se a mesma favorecia a aprendizagem da linguagem escrita e a interação social de alunos com deficiência intelectual em contexto de inclusão escolar. O estudo demonstrou que a aprendizagem cooperativa contribui de forma importante para a evolução da língua escrita, a participação e interação de alunos com deficiência intelectual na sala de aula do ensino comum. De acordo com os autores comportamentos de inibição que foram manifestados no início da pesquisa cederam lugar a comportamentos de interação positiva ao termino da pesquisa. Os alunos sem deficiência demonstraram muito mais abertura em relação aos colegas com deficiência intelectual. Eles passaram a oferecer ajuda e solicitar a opinião do colega com deficiência que por sua vez passaram a expressar suas ideias e argumentações. No que consiste a aos comportamentos relativos a participação nas atividades de escrita os autores ressaltam que uma conquista importante se verifica no momento em que os alunos com deficiência passam do status de escriba para o de autores de ideias (FIGUEIREDO, 2015). 
O estudo acima referido confirma o que outras pesquisas já indicaram: que a classe comum se revela um meio que favorece a aprendizagem da língua escrita por alunos com deficiência intelectual. $\mathrm{O}$ estudo indica ainda que a aprendizagem cooperativa se mostra como abordagem pedagógica importante contribuindo especialmente na qualidade das interações sociais estabelecidas na classe. Os alunos sem deficiência desenvolveram habilidades de apoiar e de colaborar com os colegas com deficiência intelectual, assim como, avançaram na qualidade da mediação e diminuíram gradualmente comportamentos inibidores da comunicação de seus pares. Por outro lado, os alunos com deficiência intelectual aprenderam a expressar suas opiniões e a defendê-las. Eles progrediram também no que consiste a comunicação e a autonomia (FIGUEIREDO, 2015). É importante ressaltar que a aprendizagem cooperativa requer o desenvolvimento de habilidades sociais pelos estudantes, essas habilidades devem ser aprendidas e os professores não podem as negligenciar durante a mediação. Em nenhum caso, esta mediação deve favorecer a superproteção "especialmente porque os alunos com deficiência intelectual testemunham frequentemente forte dependência em relação ao meio quando estão em situação de aprendizagem ou de resolução de problemas" (POULIN et al, 2014, p. 196, tradução livre).

Segundo Figueiredo (2015), outras abordagens focalizando o processo de ensinar e de aprender no contexto das diferenças têm sido propostas com o intuito de promover praticas pedagógicas para a escola inclusiva. Poulin (2010) apresenta a pedagogia da contribuição, Rousseau e Prud'home (2010) a pedagogia inclusiva, e a pedagogia universal e Ouellet (2014), a pedagogia criativa. De acordo com Ouellet (2014) todas essas propostas de estratégias de ensino fazem apelo aos professores para uma reflexão coletiva sobre a renovação das práticas educativas.

Qualquer que seja a abordagem adotada com o propósito de inovação pedagógica é inegável a constatação de que na escola a criança estabelece vínculos com a cultura e com o universo simbólico reagindo às relações humanas em um movimento concreto de influenciar e ser influenciada pelo outro. Aprendemos e ensinamos na escola normas, valores, 
atitudes e conhecimentos diversos. A inovação pedagógica requerida para dar conta da realidade da sociedade atual indica que a escola contemporânea enfrenta o desafio de no desenvolvimento das práticas cotidianas se transformarem para ser capaz de garantir a acessibilidade e a permanência de todas as crianças de modo que elas possam se apropriar dos bens culturais traduzidos como conhecimentos escolares (FIGUEIREDO, 2006). De acordo com Figueiredo (2006), a prática da inclusão na sociedade contemporânea requer o emprego de recursos tecnológicos e utilização de instrumentos que favoreçam o desempenho de atividades por todas as pessoas promovendo a equiparação de oportunidade que implica na acessibilidade e garante a inserção interativa de todas as pessoas na realidade sociocultural. Nesta perspectiva uma revisão na política de formação de professores se impõe aos sistemas educacionais. A escola brasileira demanda novo redimensionamento que requer mudanças estruturais com repercussão na gestão escolar e nas práticas pedagógicas.

Atualmente a política educacional brasileira aponta para a transformação da escola pública para uma escola inclusiva. Face a essa demanda, a universidade brasileira precisa transformar profundamente a sua pratica de formação inicial de professor, passando de uma formação centrada no aluno abstrato para uma formação centrada nas diferenças reais dos alunos. Essa mudança deve se apoiar em grande parte sobre experiências e conhecimentos emergentes de práticas pedagógicas voltadas para as diferenças dos alunos. Logo, há necessidade de um engajamento ativo dos atores educativos em experiências de transformação de práticas educativas no meio escolar (FIGUEIREDO, 2015).

No que consiste a formação continuada de professores diferentes concepções permeiam o meio acadêmico como, por exemplo: 1- a formação através de cursos, seminários e ateliers que se constituem no formato mais tradicional e 2- a implicação dos professores em projetos de pesquisa colaborativa ou projetos de extensão.

Segundo Beaupré e Poulin (2006), o segundo formato de formação de professores é muito mais eficiente para atender as diferenças, porque se apoia no fato que o professor exerce um papel central na própria 
formação, ele é o mobilizador de sua mudança. Para Andrade (2008), existem relações de influências mútuas definidas em termos de continuidades, descontinuidades e rupturas entre as redes de ensino e a ação dos professores quanto à educação inclusiva. Não há homogeneidade nos discursos nem nas práticas pedagógicas. Assim, as iniciativas de oferta de formação continuada aos professores devem ser flexíveis, pois o cotidiano escolar é fluído e em contínua transformação. Todavia, tanto a formação inicial quanto a formação continuada devem se respaldar em uma concepção de ensino que contemple as diferenças dos alunos, priorizando a prática de reflexão sobre a experiência e a ação docente abordando conhecimentos sobre a identidade e as diferenças dos alunos e sobre as características de ambientes escolares inclusivos.

\section{Considerações finais}

A educação inclusiva é baseada, em primeiro lugar, e, sobretudo, na ideia de que a escola deve ser um lugar de aprendizagem e de desenvolvimento que rejeita qualquer forma de discriminação ou segregação. Neste contexto, o professor responsável pelo ensino trabalha com um grupo de estudantes da mesma idade, independentemente das características individuais dos alunos que compõem este grupo. As diferenças, nestes casos, são valorizadas, são consideradas força, um contexto particularmente favorável para o desenvolvimento cognitivo, afetivo e social de todos os alunos.

As estratégias de ensino podem variar muito no contexto da educação inclusiva. O professor às vezes apela ao ensino individualizado, em outras vezes em grande grupo ou, em certos momentos, utiliza diferentes estratégias com base na cooperação entre os alunos. Mas não é da variedade de estratégias de ensino que o professor vai se valer que importa verdadeiramente quando se trata de educação inclusiva. O que importa antes de tudo é o espírito a partir do qual estas estratégias são utilizadas. $\mathrm{Na}$ verdade, a educação inclusiva está profundamente enraizada no respeito e na valorização das diferenças. A ação educativa do professor 
deve se constituir de uma reflexão, permitindo que cada membro desta comunidade de alunos descubra gradualmente a importância da sua própria participação ou a contribuição para si e para os outros no desenvolvimento do grupo. A interação social deve ser, portanto, proeminente na sala de aula inclusiva. Molina Y Garcia e Alban-Metcalfe (1998) falam de educação interativa e as diferentes estratégias de ensino, independentemente da sua natureza, devem, permanentemente, levar à construção de conhecimento no e para o social. A sala de aula inclusiva se constrói basicamente num ambiente onde o aluno, independentemente de suas competências e habilidades, será capaz de se ver como um indivíduo que contribui para o desenvolvimento dos conhecimentos coletivos e colher para si muitos benefícios que fortaleçam seu desenvolvimento intelectual e social. Esta contribuição, ou dizendo em outras palavras, esta participação no desenvolvimento do conhecimento, saber fazer e saber coletivo, bem como o reconhecimento desta contribuição pelos outros, constituem fatores determinantes para a valorização do papel social para todos os alunos e especialmente para aqueles que estão em situação de risco, a caminho da exclusão social. A valorização do papel social do estudante é de fato um desafio da educação inclusiva e a pedra angular de inclusão social. A partir desta perspectiva, convém, em primeiro lugar se perguntar se não seria mais justo falar de "Pedagogia da Contribuição" do que de uma pedagogia da inclusão (POULIN, 2010).

Como já foi referido neste texto, vários países, incluindo o Brasil, têm se engajado com ações pela implantação de um sistema de educação inclusiva. Ações estas que se vêm diante de um verdadeiro desafio uma vez que as práticas educacionais que prevalecem nas escolas ainda contam frequentemente, com um sistema padrão que promove a concorrência entre os estudantes em detrimento da colaboração. Mudanças pedagógicas profundas são, portanto, necessárias para a efetivação de práticas de educação inclusiva que se baseiam mais na ideia de "desnormatização", para usar o termo de Aucoin e Vienneau (2015). Essas transformações não podem ser concretizadas sem que sejam revistos com profundidade os programas de formação inicial e desenvolvimento do corpo docente. 
Programas estes, nos quais, frequentemente a questão da educação inclusiva é abordada de forma muito pontual (VAILLANT, 2011; DORÉ, POULIN e WAGNER, 2001). Nestes programas normalmente os modelos de educação são apresentados sem que seja estabelecida qualquer conexão com a questão da educação inclusiva. Como em tal situação, é possível desenvolver nos professores atitudes e competências necessárias para a implementação da educação inclusiva? O sucesso de tal empreendimento implica que a comunidade acadêmica assuma uma visão renovada da escola, de suas práticas e seus valores.

A reflexão construída neste texto leva a se concluir que a ação da educação inclusiva, de um lado, se apresenta frente a fortes desafios, mas de outro, mostra um caminhar animador e ótimas perspectivas. Ou seja, se de um lado a partir da epistemologia clássica da educação centralizando a ação da escola na homogeneidade, funcionalidade e evolução, se contrapondo assim com o pressuposto básico da educação inclusiva a partir do qual as diferenças e desigualdades sociais se constituem em fatores construtivos, por meio de trocas de experiências advindas das diferentes vivências das diferenças e singularidades, de outro lado, para além da institucionalidade da escola age o mundo social criando assim caminhos que viabilizam a educação inclusiva, tanto do ponto de vista dos dispositivos legais quanto da própria ação escolar.

\section{Referências}

ANDRADE, S. G. Inclusão escolar e formação continuada de professores: Relações e contrapontos. Poiésis,Tubarão, n. 1, v. 1, p. 86-100, jan./abr. 2008, p. 86-100.

AUCOIN, A.; VIENNEAU, R. L'inclusion scolaire et la dénormalisation: proposition d'un nouveau paradigme. In: ROUSSEAU, N. (Org) La pédagogie de l'inclusion scolaire. $3^{\mathrm{a}}$ édition. chap. 3. Québec: Presses de l'Université du Québec. 2015. p. 65-87. 
BEAUPRÉ, P.; POULIN, J-R. Perfectionnement des enseignants dans le domaine de l'intégration scolaire au Québec: état de la situation et pistes d'action. In: GASCON, H.; POULIN, J-R.; DETRAUX, J-J.; BOISVERT, D.; HEALEWYCK, M-C. (Édits). Déficience intellectuelle: savoirs et perspectives d'action. Vol. 2. Cap-Rouge (Québec): Presses Inter Universitaires. 2006. p. 25-34.

BONETI, L. W. O Debate sobre as Desigualdades e Diferenças Sociais na educação no Brasil: significados e contradições. Revista Perspectiva. Vol. 31. n. 1. Florianópolis: Centro de Ciências da Educão - UFSC. 2013.

BRASIL. Convenção sobre os Direitos das Pessoas com Deficiência (2006). Protocolo Facultativo à Convenção sobre os Direitos das Pessoas com Deficiência. Tradução Oficial/Brasil. Brasília: CORDE/SICORDE, Set/2007.

BRASIL, Decreto 6.571/08 de 17 de setembro de 2008. Política Nacional de Educação Especial na perspectiva da educação inclusiva. Brasília: Secretaria de Educação Especial/MEC, 2008.

DORÉ, R.; POULIN, J-R.; WAGNER, S. L'intégration scolaire et la formation à l'enseignement. Revue francophone de la déficience intellectuelle. Actes du Colloque Recherche Défi. 2001. p. 44-49.

FIGUEIREDO, R. V. O ato pedagógico como possibilidades de prazer, engajamento e significado: possibilidades de inclusão no contexto da exclusão social. Diálogo Educacional. Curitiba. v. 6. n.17. jan/abr. 2006. p.11-20.

FIGUEIREDO, R. V.; BONETI, L. W.; POULIN, J-R. Novas Luzes sobre a Inclusão Escolar. Fortaleza: Edições UFC. 2010.

FIGUEIREDO, R V. A escola de atenção às diferenças. In: FIGUEIREDO, R. V.; POULIN, J-R; BONETI, L. W. (Orgs.). Novas Luzes sobre a Inclusão Escolar. Fortaleza: Edições UFC. 2010. p.

FIGUEIREDO, R. V. Desafios da Didática diante das Políticas de Inclusão: um novo olhar sobre o ensinar e o aprender. In: CAVALCANTE, Maria Marina Dias; SALES, José Albio Moreira de; FARIAS, Isabel Maria Sabino de; LIMA, Maria Socorro Lucena. Didática e Prática de Ensino: diálogos sobre a Escola, a Formação de Professores e a Sociedade. Fortaleza: CE: EdUECE, 2015. p. 1-17. 
HABERMAS, J. Técnica e Ciência como «Ideologia». Lisboa: Edições 70. 2001 MOLINA Y GARCIA, S.; ALBAN-METCALFE, J. Integrated or inclusive education versus interactive education: the need fora new model. European journal of special needs education. vol. 13 n. 2. 1998. p. 170-179.

MOREAU, A. C. Enseignante et enseignant inclusifs. In: ROUSSEAU, N. (dir.). La pédagogie de l'inclusion scolaire: piste d'action pour apprendre tous ensemble. 2e éd. Québec. Presses de l'Université du Québec. 2010. p. 147-168.

MOREAU, A. C.; STANKÉ, B.; LAFONTAINE, L. Écoles inclusives fonctionnant en communauté d'apprentissage professionnelle comme intervention novatrice: retombées sur les apprentissages en littératie. In: BEAUPRÉ, P. Déficience intellectuelle et autisme. Presses de l'Université du Québec, Québec, 2014, p. 7-44.

ORGANIZAÇÃO DAS NAÇÕES UNIDAS (ONU). Convenção sobre os direitos das pessoas com deficiência. 2006. Disponível em: http://portal.mec.gov.br/index. php?option=com_docman\&view=download\&alias=424-cartilha-c\&category_ slug=documentos-pdf\&Itemid=30192. Acesso em: 20 de agosto de 2016.

OUELLET, S. Pédagogie Créative pour soutenir la participation sociale de l'élève ayant une déficience intellectuelle associe `a de multiples handicapes. In: BEAUPRÉ, P. Déficience intellectuelle et autisme. Presses de l'Université du Québec. Québec. 2014. p. 235-253.

POULIN, J-R. Quando a escola permite a contribuição no contexto das diferenças. In: FIGUEIREDO, R. V.; BONETI, L. W.; POULIN, J-R. (Org.). Novas luzes sobre a inclusão escolar. Fortaleza: Edições UFC. 2010. p. 17-50.

POULIN, J-R.; FIGUEIREDO, R. V.; SILVA, C. B.; GOMES, Adriana L. L. Expérience d'apprentissage d'inspiration socioconstructiviste de la langue écrite chez les élèves ayant une déficience intellectuelle intégrés en classe ordinaire. In: BEAUPRÉ, P. Déficience intellectuelle et autisme. Québec: Presses de l'Université du Québec, 2014, p. 170-209. 
ROUSSEAU, N.; PRUD'HOMME, L. C'est mon école à moi aussi: dialogue sur les caractéristiques essentielles de l'école inclusive. In: ROUSSEAU, N. (dir.). La pédagogie de l'inclusion scolaire: pistes d'action pour apprendre tous ensemble. Québec: Presses de l'Université du Québec. 2010. p. 7-46

SANTOS, B. de S. Introdução a uma ciência pós-moderna. Porto: Afrontamento, 1987.

UNESCO. 2009 World Conference on Higher Education: the new dynamics of higher education and research for societal change and development. Paris: Unesco, 2009. Disponível em: http://www.unesco.org/fileadmin/MULTIMEDIA/HQ/ ED/ED/pdf/WCHE_2009/FINAL\%20COMMUNIQUE\%20WCHE\%202009.pdf. Acesso em: 22 de agosto de 2016.

VAILLANT, D. Preparing teachers for inclusive education in Latin America, Quarterly Review of Comparative Education, 2011.

Recebido: 15/08/2016

Received: 08/15/2016

Aprovado: 10/09/2016 Approved: 09/10/2016 
